\title{
Quantification of humic acids in surface water: effects of divalent cations, $\mathrm{pH}$, and filtration $\dagger$
}

\author{
Alexandrina Rodrigues, ${ }^{a}$ António Brito, ${ }^{a}$ Peter Janknecht, ${ }^{b}$ Maria Fernanda Proença ${ }^{c}$ and Regina Nogueira ${ }^{\star a}$ \\ Received 15th July 2008, Accepted 27th October 2008 \\ First published as an Advance Article on the web 28th November 2008 \\ DOI: 10.1039/b811942b
}

Humic acids (HAs) content of raw water is an important analytical parameter in water treatment facilities because HAs in the presence of chlorine may lead to the formation of dangerous by-products (e.g., trihalomethanes). The concentration of HAs in water is not directly accessible by common analytical methods due to their heterogeneous chemical structure. The aim of this study was to compare two methods to assess humic acids (HAs) in surface water namely absorbance of ultraviolet light at $254 \mathrm{~nm}\left(\mathrm{UV}_{254}\right)$ and total organic carbon (TOC), as well as to evaluate the effects of calcium and magnesium concentrations, $\mathrm{pH}$ and sample filtration on the methods' results. An aqueous solution of a commercial HA with $10 \mathrm{mg} \mathrm{L}^{-1}$ was used in the present work. Quantification of the HA was carried out by both $\mathrm{UV}_{254}$ and TOC (combustion-infrared method) measurements. $\mathrm{UV}_{254}$ results were converted to TOC using a calibration curve. The effects of calcium $\left(0-136.3 \mathrm{mg} \mathrm{L}^{-1}\right)$ and magnesium $\left(0-34.5 \mathrm{mg} \mathrm{L}^{-1}\right)$ concentrations, $\mathrm{pH}\left(4.0,7.0\right.$ and 9.0) and sample filtration on $\mathrm{UV}_{254}$ and TOC measurements of the HA suspension were evaluated. More accurate TOC values of HA suspensions were obtained by the combustion-infrared method than by the $\mathrm{UV}_{254}$ absorbance method. The higher differences of TOC values between unfiltered and filtered samples were detected in the presence of calcium at $\mathrm{pH} 9.0$ using the spectrophotometric method.

\section{Introduction}

Natural organic matter (NOM) concentration in surface water typically ranges from $0.1 \mathrm{mg} \mathrm{L}^{-1}$ to $20 \mathrm{mg} \mathrm{L}^{-1}$ and is mainly composed of humic substances (HSs). ${ }^{1}$ HSs composition varies from source to source as they result from microbiological, chemical and photochemical transformations of plant and animal residues. ${ }^{2}$ The main constituents of HSs include aromatic and aliphatic structures as well as carboxylic, phenolic-OH, amino and quinone groups. These groups may be evaluated by nuclear magnetic resonance (NMR) spectroscopy which is by far the single most powerful tool for structural HSs studies. ${ }^{3}$ The fraction of HSs that is soluble at high $\mathrm{pH}$ but insoluble under acid conditions is denominated as humic acids (HAs). ${ }^{4}$ In general, HAs present in surface water carry an electric negative charge (zeta potential), associated to the dissociation of carboxylic and phenolic-OH groups, that can be determined by electrophoretic mobility. ${ }^{5,6}$ In the presence of divalent cations (e.g. calcium), HAs form intramolecular and intermolecular aggregates due to charge neutralization and functional group bridging. ${ }^{7,8}$

${ }^{a} I B B$ - Institute for Biotechnology and Bioengineering, Centre of Biological Engineering, University of Minho, Campus de Gualtar, 4700-057 Braga, Portugal.E-mail: regina@deb.uminho.pt; Fax: +351 253604 400; Tel: +351253678986

${ }^{b}$ Stadtwerke Düsseldorf AG - Wasserwerke, Himmelgeister Landstrasse 1, 40589 Düsseldorf, Germany

${ }^{c}$ Chemistry Department, University of Minho, Campus de Gualtar, 4700057 Braga, Portugal

$\uparrow$ Electronic supplementary information (ESI) available: Results of simple mathematical model and empirical absorption model for zeta potential correlation. See DOI: 10.1039/b811942b
The HSs content of raw water is an important analytical parameter in water treatment facilities since they have been associated with the formation of carcinogenic disinfection by-products (e.g. trihalomethanes) upon chlorination of drinking water. ${ }^{9}$ The concentration of HAs in water is not directly accessible to common analytical methods due to their heterogeneous chemical structure. ${ }^{10,11}$ Instead, total organic carbon (TOC) and absorbance of ultraviolet light at $254 \mathrm{~nm}\left(\mathrm{UV}_{254}\right)$ are used as group parameters to represent the concentration of HSs in water. ${ }^{12,13}$ Spectrophotometry utilizes the capacity of HSs to absorb ultraviolet light at $254 \mathrm{~nm}$, which increases with their content of aromatic rings, the ratio between aromatic and aliphatic carbon, the total carbon content in the water, and the molecular weights of the HSs. ${ }^{10}$ Given stable absorption characteristics, the UV light absorbance of HSs at a specific wavelength is proportional to their concentration according to Beer's law. TOC content has been widely used as a standard method for monitoring NOM in surface waters. ${ }^{14}$ This method is able to monitor organic carbon independently of their molecular configuration; therefore the chemical reaction between constituents has less influence in the accuracy of the results than the same results obtained by the spectrophotometric method. Comparing their practical application, the spectrophotometric method requires less expensive equipment than the TOC method (sample combustion followed by infrared $\mathrm{CO}_{2}$ detection). It is also easier to maintain and operate, as the only sample pretreatment necessary is filtration and the time necessary to analyze each sample is approximately one minute. ${ }^{15}$ The main disadvantage of spectrophotometry, however, is its possible corruption by chemical reaction between constituents of the solution, namely molecular aggregations. 
Although several investigations have reported either on the quantification of HSs using ultraviolet UV and TOC methods or on the aggregation of HSs under certain environmental conditions, little attention has been given to the effect of divalent cations (namely calcium and magnesium), sample pre-treatment and $\mathrm{pH}$ on these methods' results. ${ }^{16-23}$ The aim of this study was to compare two methods to assess humic acids (HAs) in surface water, namely absorbance of ultraviolet light at $254 \mathrm{~nm}\left(\mathrm{UV}_{254}\right)$ and total organic carbon (combustion-infrared method), as well as to evaluate the effects of calcium and magnesium concentrations, $\mathrm{pH}$ and sample filtration on the methods' results.

\section{Materials and methods}

\section{Humic acid characterization}

A commercial humic acid (HA) from Fluka (commercialized by Sigma Aldrich, 53680 Humic acid) was used to simulate humic substances (HSs) in surface water. Its elemental composition was determined with an elemental analyzer (Carlo Erba, model EA 1108). Functional groups were identified by ${ }^{13} \mathrm{C}$ solid-state and ${ }^{1} \mathrm{H}$ solution nuclear magnetic resonance (NMR). ${ }^{13} \mathrm{C}$ NMR was carried out using a Brucker MSL 400P operated at ${ }^{13} \mathrm{C}$ frequency of $100.63 \mathrm{MHz}$ and magic-angle spinning rate (MAS) of $6.0 \mathrm{kHz}$. The solid HA samples were filled into a $4 \mathrm{~mm}$ diameter $\mathrm{ZrO}_{2}$ rotor with a Kel-F cap (1.2 s recycle time and $1 \mathrm{~ms}$ contact time). Each spectrum consisted of 2400 data points and the chemical shifts were referenced externally to glycine (176.03 ppm). ${ }^{1} \mathrm{H}-$ NMR was carried out using a Varian Unity Plus 300 spectrometer NMR with a $5 \mathrm{~mm}$ probe head. The solid HA, $20 \mathrm{mg}$, was dissolved in $1 \mathrm{~mL}$ of dimethylsulfoxide (DMSO- $d_{6}$ ) and deuterated sodium hydroxide solution $\left(\mathrm{NaOD} / \mathrm{D}_{2} \mathrm{O}\right)$ and was used for standard measurements ( $45^{\circ}$ pulse acquisition, $1 \mathrm{~s}$ delay).

\section{Experimental design}

Total organic carbon concentration of HA solutions $(10.0 \mathrm{mg}$ $\mathrm{L}^{-1} \mathrm{C}$ ) in the presence of different concentrations of calcium $\left(0-136.3 \mathrm{mg} \mathrm{L}^{-1}\right)$ and magnesium $\left(0-34.5 \mathrm{mg} \mathrm{L}^{-1}\right)$ ions, at three $\mathrm{pH}$ values (4.0, 7.0 and 9.0) was directly measured by the combustion-infrared method and indirectly determined by UV spectroscopy at $254 \mathrm{~nm}$. Unfiltered and filtered samples were analyzed. Filtered samples were obtained using a $0.45 \mu \mathrm{m}$ filter (514-4156 Membrane disc filters Supor-450, VWR). Experiments were performed in triplicate.

\section{Humic acid solutions}

A concentrated stock solution was prepared by dissolving 206.8 $\mathrm{mg}$ of humic acid (HA) in $1 \mathrm{~L}$ of an aqueous solution of $4.0 \mathrm{~g} \mathrm{~L}^{-1}$ of $\mathrm{NaOH}$. The stock solution was stored in the dark at $4{ }^{\circ} \mathrm{C}$. A series of solutions were prepared by dissolving a weighed amount of $\mathrm{CaCl}_{2} \cdot 2 \mathrm{H}_{2} \mathrm{O}$ or $\mathrm{MgSO}_{4} \cdot 7 \mathrm{H}_{2} \mathrm{O}$ (Sigma Aldrich, p.a.) in a tenfold dilution of the $\mathrm{HA}$ stock solution $\left(20.7 \mathrm{mg} \mathrm{L}^{-1}\right.$ final concentration or $10.0 \mathrm{mg} \mathrm{L}^{-1}$ carbon). Experiments were performed at three different $\mathrm{pH}$ values (4.0, 7.0 and 9.0) which were adjusted by addition of $\mathrm{HCl}\left(73.0 \mathrm{mg} \mathrm{L}^{-1}\right)$ or $\mathrm{NaOH}\left(80.0 \mathrm{~g} \mathrm{~L}^{-1}\right)$ concentrated solutions. Ultrapure water was used in the preparation of all solutions.

\section{Total organic carbon}

Total organic carbon was determined by sample combustion and infrared carbon dioxide detection (5310 B) according to Standard Methods using a Shimadzu TOC-5000A analyzer. ${ }^{24}$

\section{UV spectroscopy}

UV absorbance of humic acid solutions was carried out at $254 \mathrm{~nm}$ using a single beam spectrophotometer UV-160A (model STR-458) and a $1 \mathrm{~cm}$ quartz cell and the respective values were converted to total organic carbon using a calibration curve. For that purpose, serial dilutions of the concentrated HA stock solution in the range $0-41.4 \mathrm{mg} \mathrm{L}^{-1}$ (or 0-20.0 $\mathrm{mg} \mathrm{L}^{-1}$ of carbon, based on HA elemental composition) were prepared at three $\mathrm{pH}$ values namely 4.0, 7.0 and 9.0. $\mathrm{pH}$ adjustment was achieved as previously described. The mathematical relationship absorbance versus concentration is presented in Table 1 .

\section{Zeta potential of $\mathrm{HA}$ in the presence of divalent cations}

The colloid's zeta potential of HA in the presence of calcium and magnesium was determined using a Malvern Zetasizer instrument. The zeta potential cell (DTS1060) was rinsed using a disposable syringe (DTS1060) with at least $20 \mathrm{~mL}$ of each sample solution before measuring the zeta potential of the HA in the test solution. All experiments were carried out at $20^{\circ} \mathrm{C}$ using suspensions aged for $24 \mathrm{~h}$. The zeta potential was derived from the electrophoretic mobility using the Smoluchowski approximation. $^{25}$

\section{Statistical analyses}

A $t$-test was used where specific means were being compared. Acceptance or rejection of the null hypothesis was based on an $\alpha$-level of 0.05 in all cases. ${ }^{26}$

\section{Results and discussion}

\section{Humic acid characterization}

The elemental composition of the Fluka humic acid (HA) determined in the present study was $48.36 \%$ of C, $26.91 \%$ of O, $4.24 \%$ of $\mathrm{H}, 0.78 \%$ of $\mathrm{N}$ and $0.78 \%$ of $\mathrm{S}$. This result is in agreement with the one provided by Fluka $(47.9 \%$ of $\mathrm{C}, 4.91 \%$ of $\mathrm{H}$, $0.67 \%$ of $\mathrm{N}$ and $1.18 \%$ of $\mathrm{S}$ ) but both differ from the one

Table 1 Linear regression equations from standard calibration ${ }^{a}$

\begin{tabular}{lll}
\hline $\mathrm{pH}$ & Filtered sample & Unfiltered sample \\
\hline 4.0 & $A=4.69 \times 10^{-2} \mathrm{TOC}$ & $A=6.06 \times 10^{-2} \mathrm{TOC}$ \\
& $+5.10 \times 10^{-3}$ & $-4.00 \times 10^{-3}$ \\
& $R^{2}=0.9995$ & $R^{2}=0.9999$ \\
7.0 & $A=5.48 \times 10^{-2} \mathrm{TOC}$ & $A=6.33 \times 10^{-2} \mathrm{TOC}$ \\
& $-3.60 \times 10^{-3}$ & $-4.40 \times 10^{-3}$ \\
& $R^{2}=0.9998$ & $R^{2}=0.9999$ \\
9.0 & $A=5.64 \times 10^{-2} \mathrm{TOC}$ & $A=6.43 \times 10^{-2} \mathrm{TOC}$ \\
& $+1.20 \times 10^{-3}$ & $+1.00 \times 10^{-7}$ \\
& $R^{2}=0.9999$ & $R^{2}=1.0000$ \\
& & \\
${ }^{a} A:$ absorbance; & TOC: total organic carbon in $\mathrm{mg} \mathrm{L}^{-1}$. \\
\hline
\end{tabular}


published by Pluciński et al. (54.37\% of C, 39.84\% of O, $4.28 \%$ of $\mathrm{H}, 0.66 \%$ of $\mathrm{N}$ and $0.85 \%$ of $\mathrm{S}) .{ }^{27}$

To obtain additional information regarding the structure of the $\mathrm{HA}$, the atomic $\mathrm{H} / \mathrm{C}, \mathrm{N} / \mathrm{C}$, and $\mathrm{O} / \mathrm{C}$ ratios has been determined. Previous studies suggest that the $\mathrm{H} / \mathrm{C}$ ratio is an indicator of the amount of saturation of $\mathrm{C}$ atoms and/or branched structures within the molecule, the $\mathrm{N} / \mathrm{C}$ ratio is related to the amount of proteinaceous compounds, and the $\mathrm{O} / \mathrm{C}$ ratio is assumed to indicate the carbohydrate content and degree of oxidation. ${ }^{28-30}$ Literature studies reported $\mathrm{H} / \mathrm{C}$ ratio for soil $\mathrm{HAs}$ in the range of $0.78-1.60$ and for aquatic HAs between 1.23-1.46. ${ }^{31,32,28}$ Regarding the $\mathrm{O} / \mathrm{C}$ ratio, values reported for soil HAs are in the range of $0.35-0.59$ while for aquatic HAs the values are between $0.55-0.63$, respectively. The N/C ratio presented values ranging from 0.021 to 0.080 for soil HAs and from 0.036 to 0.070 for aquatic HAs. The atomic ratios determined in the present study were $1.04(\mathrm{H} / \mathrm{C}), 0.42(\mathrm{O} / \mathrm{C})$, and $0.012(\mathrm{~N} / \mathrm{C})$ which are within the values reported in the literature for soil HAs, with the exception of the N/C ratio. This value is below the lower limit reported, and probably reflects a chemical composition with a poor content of aminoacid units. Additional information on the structure of Fluka HA (Sigma-Aldrich) was obtained from FTIR and NMR results.

${ }^{13} \mathrm{C}$ Solid-state NMR and ${ }^{1} \mathrm{H}$ solution NMR spectra are depicted in Fig. 1 and Fig. 2, respectively.

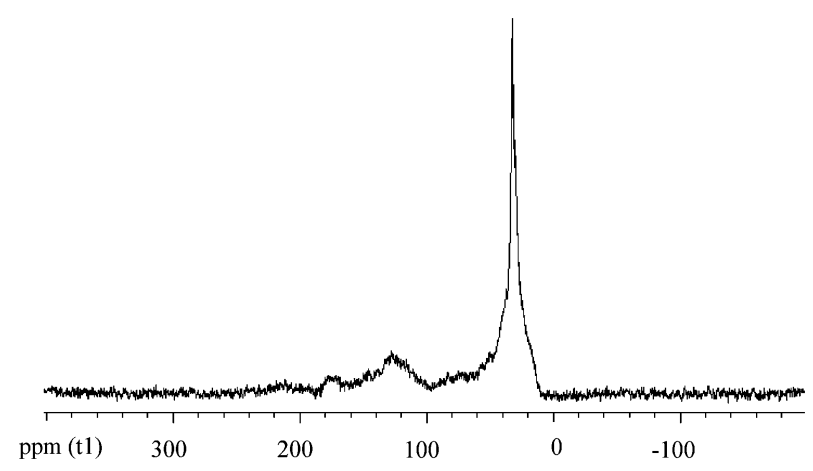

Fig. 1 Solid-state ${ }^{13} \mathrm{C}$ NMR $\left({ }^{13} \mathrm{C}-\mathrm{NMR}-\mathrm{MAS}\right)$ spectrum of the HA.

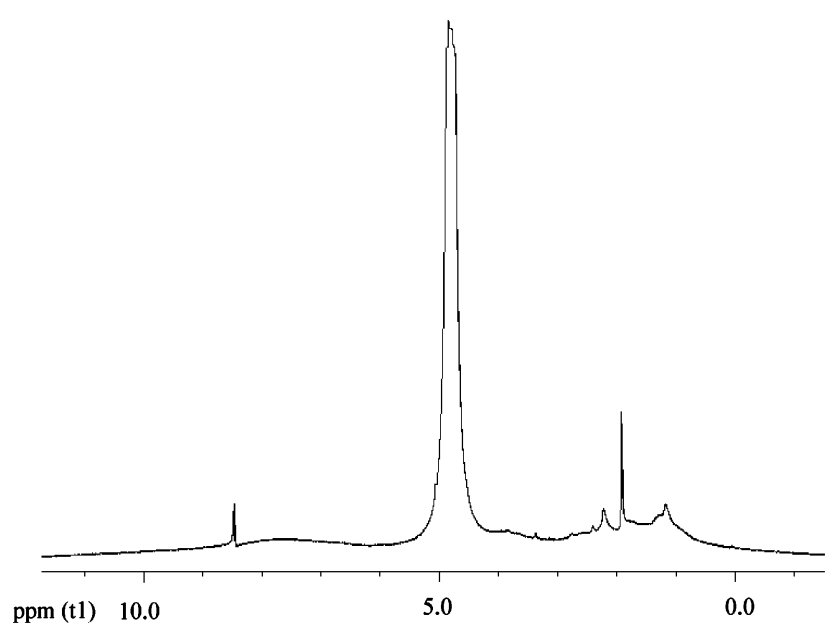

Fig. 2 Solution ${ }^{1} \mathrm{H}$ NMR spectrum of the HA.
The ${ }^{13} \mathrm{C}$ NMR spectrum shows broad signals between $\delta 10 \mathrm{ppm}$ and $225 \mathrm{ppm}$ from which a sharp and intense singlet emerges at $\delta \approx 30 \mathrm{ppm}$. This signal must be associated with an equally intense singlet in the ${ }^{1} \mathrm{H}$ NMR spectrum of the same sample at $\delta 1.93 \mathrm{ppm}$, typical of acetate methyl groups. Other sharp but less intense signals at $\delta 1.19 \mathrm{ppm}$ and $\delta 2.23 \mathrm{ppm}$ in the ${ }^{1} \mathrm{H}$ NMR spectrum may indicate that other methyl groups are present either as part of alkyl chains or linked to carbonyl, or to aromatic groups. They may be associated with two shoulders visible in the ${ }^{13} \mathrm{C}$ NMR spectrum around $\delta 25 \mathrm{ppm}$ and $35 \mathrm{ppm}$. The remaining signals in the ${ }^{13} \mathrm{C} \mathrm{NMR}$ also indicate the presence of non-polar aliphatic carbon atoms $(\delta 10-40 \mathrm{ppm}$, under the intense acetyl absorption) and $\mathrm{O}-$ alkyl/N-alkyl carbons $(\delta 40$ $90 \mathrm{ppm})$. A broad signal in the ${ }^{13} \mathrm{C}$ NMR spectrum between $\delta 100-160 \mathrm{ppm}$ indicates the presence of aromatic groups with both electron-donating (amino/alkoxy/hydroxy substituents) and electron withdrawing groups (carboxylic acids and derivatives). The presence of carbonyl groups was confirmed by the broad signal between $\delta 170-225 \mathrm{ppm}$. A similar pattern was reported in the literature for the ${ }^{13} \mathrm{C}$ NMR spectrum of a solid purified Fluka HA sample. ${ }^{33}$ In this case, five broad peaks were identified in the $0-50,50-85,85-105,105-160$ and $160-200 \mathrm{ppm}$ regions, confirming the presence of the same type of functional groups. A notorious difference observed in the present study is the sharp and intense singlet at $\delta \approx 30 \mathrm{ppm}$, assigned to the acetate methyl group. As a result, comparatively small signals are registered for the remaining regions. Broadening of this band as it reaches the baseline leads to partial overlapping with the 85-105 ppm band identified in the literature and assigned to $\mathrm{C}-\mathrm{O}$ in carbohydrate compounds.

The signals in the ${ }^{1} \mathrm{H}$ NMR spectrum are spread between $\delta$ 0.5-10 ppm and are, in general, very broad. The intense band centered at $\delta 4.8 \mathrm{ppm}$ was assigned to the water peak due to the presence of a large amount of water. In this case, hydration molecules were reinforced by water molecules formed by deuterium exchange of all the hydroxy/amino protons (of alcohols, phenols, carboxylic acids and amines) present in HA with $\mathrm{D}_{2} \mathrm{O}$ used as co-solvent. This allowed us to calculate the molar ratio of protons on saturated and unsaturated carbon atoms (approximately $2.1: 1$ ), from the integration of the signals in the $\delta 0.5-$ $4.2 \mathrm{ppm}$ and of the $\delta 5.6-10 \mathrm{ppm}$ regions respectively.

The FTIR spectrum (Fig. 3) shows an intense signal centered at $\nu 3429 \mathrm{~cm}^{-1}$ assigned to the $\mathrm{N}-\mathrm{H} / \mathrm{O}-\mathrm{H}$ stretching vibrations, confirming the presence of alcohols/phenols, amines/amides and possibly carboxylic acids. Two medium intensity peaks at $\nu 2922$ and $2852 \mathrm{~cm}^{-1}$ may be due to the $\mathrm{C}-\mathrm{H}$ stretching vibration of alkyl chains. The stretching vibration of the aromatic $\mathrm{C}-\mathrm{H}$ bonds, usually visible in the $\nu 3200-3000 \mathrm{~cm}^{-1}$ region, may be masked by the broad $\mathrm{N}-\mathrm{H} / \mathrm{O}-\mathrm{H}$ signal. An intense band at $\nu$ $1608 \mathrm{~cm}^{-1}$ can be assigned to the $\mathrm{C}=\mathrm{O}$ stretching vibration in the carboxylate function and also to the $\mathrm{C}=\mathrm{C}$ stretching vibration in the aromatic ring and alkene groups. A shoulder around $\nu 1700$ $\mathrm{cm}^{-1}$, typical of the stretching vibration of carbonyl groups of ketones (including quinones) carboxylic acids and/or amides, confirms that these units are present in humic acid. The bending vibrations of methyl and methylene groups $\left(\nu 1387 \mathrm{~cm}^{-1}\right)$ and the stretching vibration of the $\mathrm{C}-\mathrm{O}$ bond in alcohols, phenols and ethers (overlapped bands between $\nu 1000$ and $1200 \mathrm{~cm}^{-1}$ ) also support the presence of these functional groups. The main 


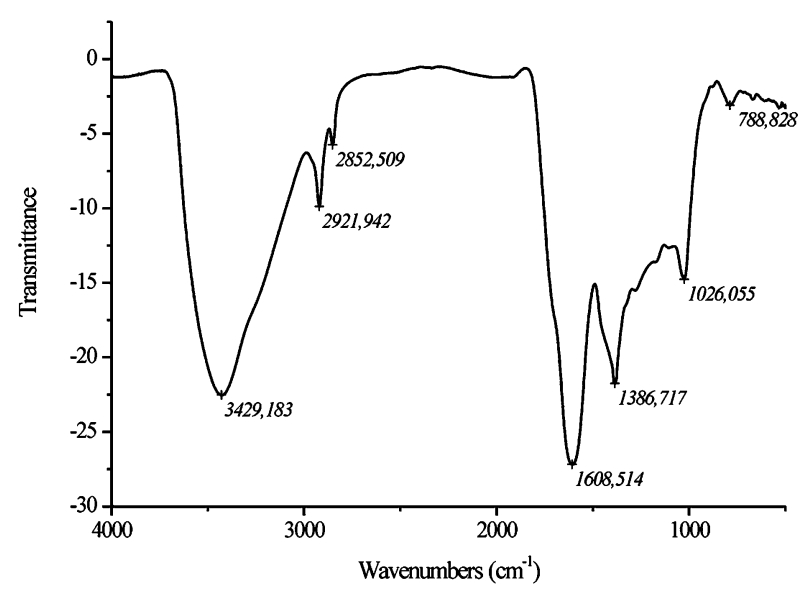

Fig. 3 FTIR spectrum of the HA.

absorbance bands and the corresponding assignments are in agreement with data reported in literature..$^{33-41}$

\section{Zeta potential as a function of $\mathrm{pH}$ and concentration of divalent cations}

Zeta potential ( $\mathrm{ZP})$ values became more negative, decreased from $-38.4 \pm 0.35 \mathrm{mV}$ to $-43.6 \pm 0.30 \mathrm{mV}$, as $\mathrm{pH}$ was increased from 4.0 to 9.0 . The variation of the colloid's zeta potential with $\mathrm{pH}$ reflects the ionization of the carboxylic and phenolic acidic groups. ${ }^{42}$ The charge, as well as intra- and intermolecular electrostatic repulsion, increases as acidic groups are ionized with increasing $\mathrm{pH}$, restricting aggregation phenomena. The effect of the concentration of divalent cations on $\mathrm{ZP}$ values at different $\mathrm{pH}$ values is depicted in Fig. 4 for calcium and in Fig. 5 for magnesium.

The results show that $\mathrm{ZP}$ values increase (become less negative) with increasing calcium and magnesium concentrations, which can be explained by HA's charge reduction due to metal ions binding to the negatively charged carboxylic groups. ${ }^{43,44,23}$ The magnitude of the zeta potential gives an indication of the potential stability of the colloidal system. A dividing line between stable and unstable aqueous dispersions is generally taken at either +20 or $-20 \mathrm{mV}$. Colloids with $\mathrm{ZP}$ more positive than +20

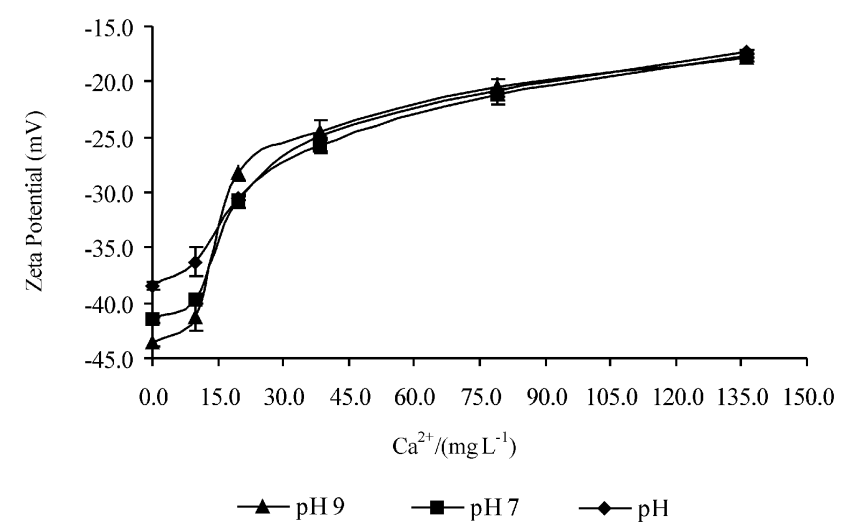

Fig. 4 Zeta potential of the HA suspension (10.0 $\mathrm{mg} \mathrm{L}^{-1}$ carbon) as a function of $\mathrm{pH}$ at several calcium concentrations.

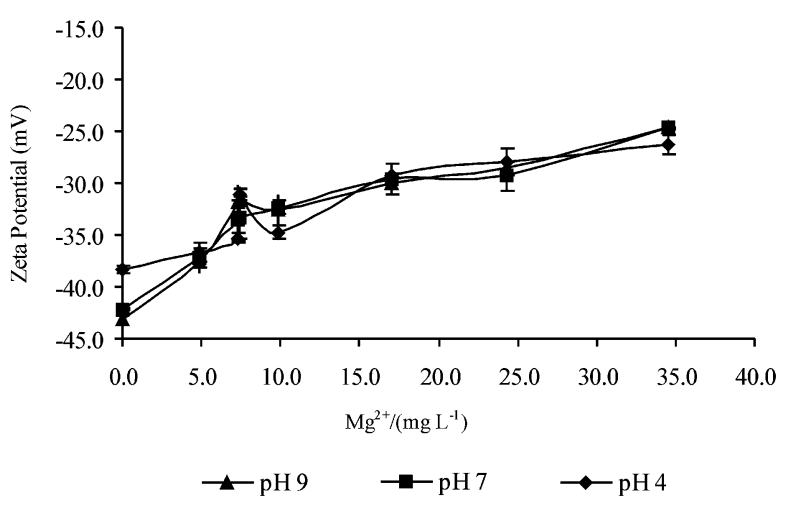

Fig. 5 Zeta potential of the HA suspension (10.0 $\mathrm{mg} \mathrm{L}^{-1}$ carbon) as a function of $\mathrm{pH}$ at several magnesium concentrations.

$\mathrm{mV}$ or more negative than $-20 \mathrm{mV}$ are normally considered stable. ${ }^{45}$ The DVLO theory says that the stability of a colloidal system is determined by the sum of the electrical double layer repulsive and van der Waals attractive forces which the particles experience as they approach one another. ${ }^{46,47}$ In practice, the repulsive forces can be greatly affected by changing the ionic strength of the dispersion medium. In this study, at a calcium concentration of $136.3 \mathrm{mg} \mathrm{L}^{-1}$ there was dispersion instability, the $\mathrm{ZP}$ was $-17.3 \pm 0.20 \mathrm{mV}$ at $\mathrm{pH} 4.0,-17.6 \pm 0.21 \mathrm{mV}$ at $\mathrm{pH}$ 7.0 and $-17.9 \pm 0.25 \mathrm{mV}$ at $\mathrm{pH} 9.0$, and, therefore, the colloids in the dispersion adhered together and formed visible aggregates. A conclusion, which can be drawn from these results, is that the HA's zeta potential increases with increasing calcium and magnesium concentrations.

\section{Monitoring humic material in the presence of divalent cations}

Total organic carbon (TOC) values obtained directly by sample combustion and infrared $\mathrm{CO}_{2}$ detection and indirectly by UV spectroscopy at $254 \mathrm{~nm}$ (as described in materials and methods: total organic carbon and UV spectroscopy, respectively) were used as surrogates for HA quantifications. The effect of $\mathrm{pH}$, concentration of divalent cations and sample filtration on TOC values, determined by both methods, is depicted in Fig. 6 for calcium and in Fig. 7 for magnesium.

Control measurements carried out with pure solutions of calcium chloride and magnesium sulfate at the concentrations in question never yielded TOC values above $0.08 \mathrm{mg} \mathrm{L}^{-1}$, so that direct influence of these substances in both methods was considered negligible. In most cases unfiltered samples presented considerably higher TOC concentrations than filtered ones independently of the method used, the concentration of divalent cations and the $\mathrm{pH}$ values. These results evidenced that a considerable portion of molecules were removed in the filtration process. Two hypotheses may explain the strong removal of organic carbon in the filtration process. The first hypothesis suggests that the presence of divalent cations enhances aggregation of HAs due to charge neutralization and functional group bridging; aggregates are more readily removed by filtration. ${ }^{8}$ This hypothesis is corroborated by the observed increase of the zeta potential (became less negative) with increasing concentrations of calcium and magnesium (Fig. 4, 5) that indicated suspension instability. The second hypothesis is based on the adsorption of 

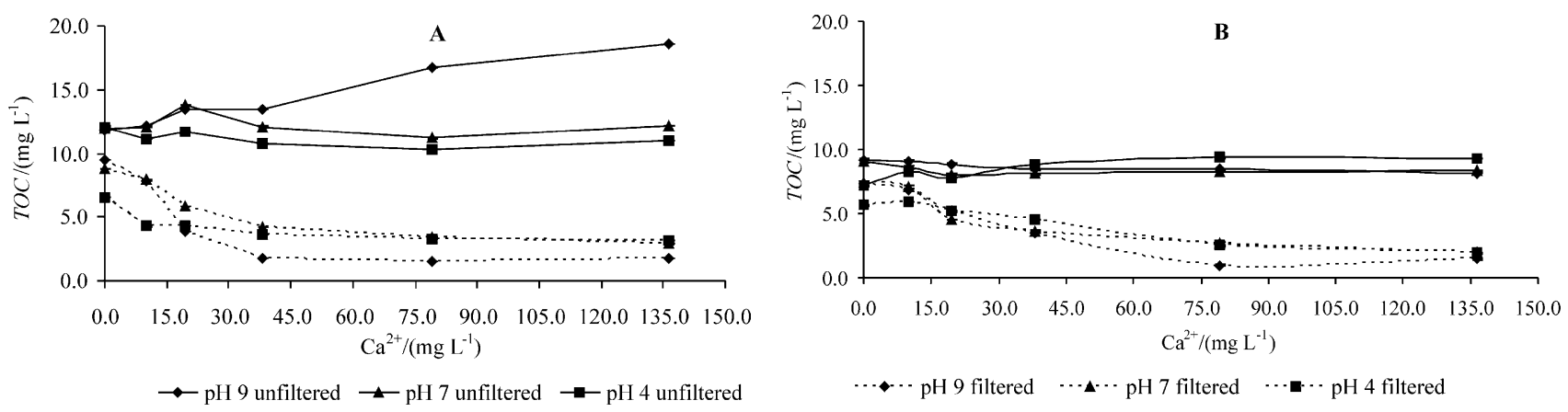

Fig. 6 Effect of calcium on total organic carbon concentration of the HA suspension ( $10.0 \mathrm{mg} \mathrm{L}^{-1}$ carbon) determined by: (A) spectrophotometric method; (B) combustion-infrared method.
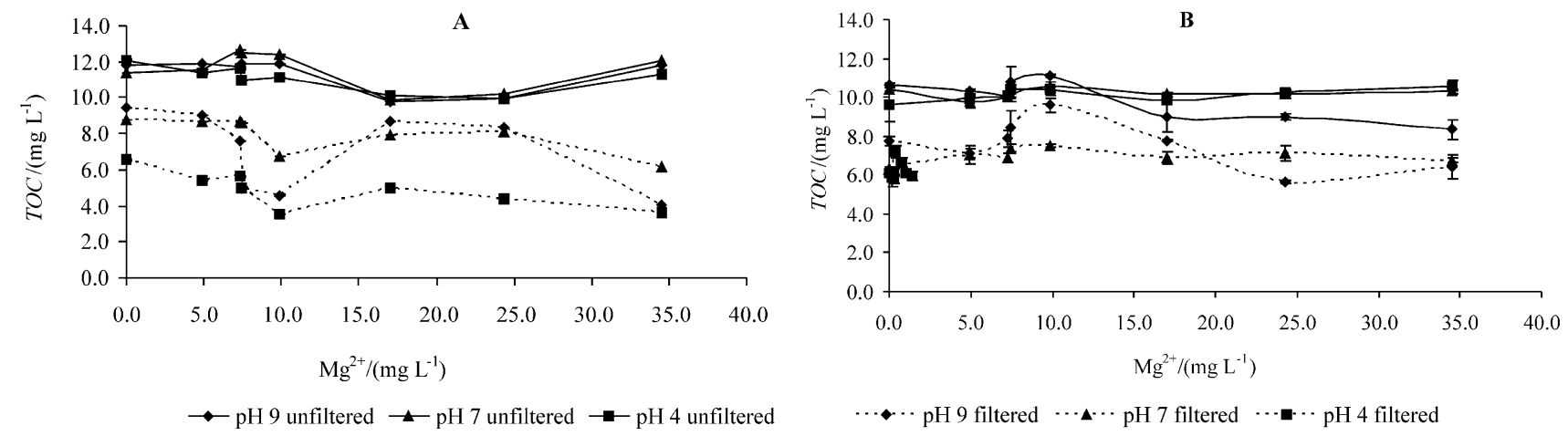

Fig. 7 Effect of magnesium on total organic carbon concentration of the HA suspension (10.0 $\mathrm{mg} \mathrm{L}^{-1}$ carbon) determined by: (A) spectrophotometric method; (B) combustion-infrared method.

HA molecules onto the filtration membrane. As pointed out in several studies the adsorption of HAs increases with increasing concentrations of the metal ions, which shield the electrostatic repulsion among HA molecules and thus facilitate their deposition on the membrane surface. ${ }^{48,49,16}$

Differences in TOC results between spectrophotometric versus combustion-infrared methods were detected mainly for unfiltered samples, and specifically in the presence of calcium at both pH 7.0 and 9.0, which is in keeping with the different basic measurement principles. The principle of the spectrophotometer is based on Beer's law: the absorbance of a compound at a specific wavelength is proportional to the concentration of the compound. ${ }^{15}$ This law is only valid when all of the constituents in the sample have no chemical reaction between each other which was not the case in the present study. Calcium ions interacted with the HA and molecular aggregation was promoted with the consequent increase in turbidity, principally, at basic $\mathrm{pH}$. The higher TOC results obtained by the spectrometric method might thus be explained by light scattering effects. ${ }^{9}$ The principle of the combustion-infrared method is the oxidation of organic carbon to $\mathrm{CO}_{2}$ by combustion, therefore, the molecular structure as well as molecular interactions do not influence the TOC measurement.

It is important to stress that UV spectroscopy $(254 \mathrm{~nm})$ and combustion-infrared methods are based on different principles, while the first method measures the amount of aromatic structures, ${ }^{50}$ the second method quantifies carbon independently of the molecule's chemical structure. The use of UV spectroscopy to monitor natural organic matter in surface water is a fast and relatively inexpensive method that gives information about the aromatic content as well as the total organic content (when associated with a standard calibration curve). However, the results should be interpreted with care since the presence of calcium and magnesium ions and the $\mathrm{pH}$ interfere with the analysis' results.

To compare both analytical methods, the errors associated with the determination of TOC of an unfiltered aqueous suspension of HA with a carbon concentration of $10.0 \mathrm{mg} \mathrm{L}^{-1}$ at $\mathrm{pH} 7.0$ were compared. The results were $10.3 \pm 2.0 \mathrm{mg} \mathrm{L}^{-1}$ for the combustion-infrared method and $11.9 \pm 0.1 \mathrm{mg} \mathrm{L}^{-1}$ by the UV spectroscopy method. The combustion-infrared method gave the most accurate value although the precision was lower than the one obtained in the UV spectroscopy method. Moreover, the combustion-infrared method provided the least changes for unfiltered and filtered samples in the presence of divalent cations, at different $\mathrm{pH}$ values.

Surface water may present a highly variable composition regarding calcium (1.6- $\left.413.5 \mathrm{mg} \mathrm{L}^{-1}\right)$ and magnesium (1.6-259.2 $\left.\mathrm{mg} \mathrm{L}^{-1}\right)$ concentrations and $\mathrm{pH}$ values $(2.5-8.2) .{ }^{51-54}$ Thus, the combustion-infrared method is recommended for HA quantification in surface water.

\section{Conclusions}

From this work's results can be concluded that humic acids monitoring with respect to its total organic carbon content 
(TOC) by different methods leads to different results. Unfiltered samples presented considerably higher total organic carbon (TOC) values than filtered ones, independently of the method used. The higher differences of TOC values between unfiltered and filtered samples were detected in the presence of calcium at pH 9.0 using the spectrophotometric method. The UV spectroscopic method gives information about the aromatic content of the sample, unlike the combustion infrared method, but suffers from interferences resulting from molecular aggregation in the presence of divalent cations. The combustion-infrared method gave the most accurate values although the precision was lower than the one obtained in the UV spectrophotometric method. In this regard and due the fact that $\mathrm{pH}$ values and divalent cations concentration in surface water may vary considerably, the combustion-infrared method is recommended for HSs quantifications in surface water.

\section{Acknowledgements}

The work described in this paper was financially supported by FCT - Foundation for Science and Technology (Portugal) - by the PhD student grant SFRH/BD/18565/2004. This support is gratefully acknowledged.

\section{References}

1 C. J. Volk, in Methods in Enzymology, Microbial growth in biofilms. ed. R. J. Doyle, Academic Press, New York, NY. 2001, 337, 144.

2 A. L. Rose and T. D. Waite, Marine Chem., 2003, 84, 8.

3 A. J. Simpson, Magn. Reson. Chem., 2002, 40, S72.

4 F. Claret, T. Schäfer, A. Bauer and G. Buckau, Sci. Total Environ., 2003, 317, 189.

$5 \mathrm{~J} . \mathrm{H}$. Weber, in Humic substances and their role in the environment, ed. F. H. Frimmel and Christman, John Wiley \& Sons, Chichester, 1988, $41,165$.

6 P. Warwick, A. Hall, V. Pashley and N. Bryan, Chemosphere, 2001, 45, 303.

7 R. Wandruszka, C. Ragle and R. Engebretson, Talanta, 1997, 44, 805.

8 T. Anđelković, J. Perović, M. Purenović and D. Anđelković, Facta Universitatis Series: Physics, Chemistry and Technology, 2004, 3(1), 79.

9 G. S. Wang and T. S. Hsieg, Environ. Int., 2001, 26, 205.

10 E. Vogel, R. Geßner, M. H. B. Hayes and W. Kiefer, J. Mol. Struct., 1999, 482-483, 195.

11 M. Mertig, D. Klemm, H. Zänker and W. Pompe, Surf. Interface Anal., 2002, 33, 113.

12 I. N. Najm, N. L. Patania, J. G. Jacangelo and S. W. Krasner, J. Am. Water Works Assoc., 1994, 86(6), 98.

13 A. Eaton, J. Am. Water Works Assoc., 1995, 87(2), 86.

14 E. Tipping, A. F. H. Marker, C. Butterwick, G. D. Collett and P. A. Cranwell, Sci. Total Environ., 1997, 194, 345.

15 D. A. Skoog and J. J. Leary, Principles of instrumental analysis, 4th edn, Saunders College Publication, Philadelphia, PA, 1988.

16 Y. Wang, C. Combe and M. M. Clark, J. Membrane Sci., 2001, 183, 49.

17 A. Baker, Hydrol. Process., 2002, 16, 3203.

18 C. Volk, L. Wood, B. Johnson, J. Robinson, H. W. Zhuc and L. Kaplan, J. Environ. Monit., 2002, 4, 43.
19 D. Gan, S. I. Kotob and D. S. Walia, Ann. Environ. Sci., 2007, 1, 11.

20 M. F. Benedetti, W. H. Vanriemsdijk and L. K. Koopal, Environ. Sci. Technol., 1996, 30, 1805.

21 A. K. Pandey, S. D. Pandey and V. Misra, Ecotoxicol. Environ. Safety, 2000, 47, 195.

22 L. K. Koopal, W. H. van Riemsdijk and D. G. Kinniburgh, Pure Appl. Chem., 2001, 73(12), 2005.

23 A. Majzik and E. Tombácz, Org. Geochem., 2007, 38, 1330.

24 APHA, AWWA, WEF, Standard Methods for the Examination of Water and Wastewater, 19th edn, American Public Health Association, Washington DC, U.S.A, 1995, 5-17.

25 R. J. Hunter, Zeta Potential in Colloid Science, Principles and Applications, Academic Press, London, 1981.

26 J. C. Miller and J. N. Miller, Statistics for analytical chemistry, Ellis Horwood, 2nd edn, 1992.

27 P. Pluciński, Z. Górski and J. Sławiński, Acta Agrophys., 2007, 9(1), 191.

28 M. Giovanela, E. Parlanti, E. J. Soriano-Sierra, M. S. Soldi and M. M. D. Sierra, Geochem. J., 2004, 38, 255.

29 G. Abbt-Braun, U. Lankes and F. H. Frimmel, Aquat. Sci., 2004, 66, 151.

30 A. Santos, W. G. Botero, I. C. Bellin, L. C. Oliveira, J. C. Rocha, A. G. R. Mendonça and A. F. Godinho, J. Braz. Chem. Soc., 2007, 18(4), 824.

31 W. Geyer, L. Brüggemann and G. Hanschmann, Int. J. Environ. Anal. Chem., 1998, 71(2), 181-193.

32 L. Li, W. Huang, P. Peng, G. Sheng and J. Fu, Soil Sci. Soc. Am. J., 2003, 67, 740 .

33 J. Pertusatti and A. G. S. Prado, J. Colloid Interface Sci., 2007, 314, 484-489, and references there in.

34 M. Klavins and L. Eglite, Colloids Surfaces. A, 2002, 203, 47.

35 A. G. S. Prado, J. D. Torres, P. C. Martins, J. Pertusatti, L. B. Bolzon and E. A. Faria, J. Hazard. Mater, 2006, 136, 585.

36 A. G. S. Prado and C. Airoldi, Thermochim. Acta, 2003, 405, 287.

37 D. A. N. Ussiri and C. E. Johnson, Geoderma, 2003, 111, 123.

38 G. Palladino, D. Ferri, C. Manfredi and E. Vasca, Anal. Chim. Acta, 2007, 582, 164.

39 F. J. Stevenson, Humus Chemistry, Wiley, New York, 1982.

40 M. D. Landgraf, S. C. da Silva and M. O. D. Rezende, Anal. Chim. Acta, 1998, 368, 155.

41 J. Kucerik, J. Kovar and M. Pekar, J. Therm. Anal. Calorim, 2004, 76, 55.

42 R. A. Alvarez-Puebla and J. J. Garrido, Chemosphere, 2005, 59, 659.

43 J. Gregory and J. Duan, Pure Appl. Chem., 2001, 73(12), 2017.

44 A. I. Schăfer, R. Mauch, T. D. Waite and A. G. Fane, Environ. Sci. Technol., 2002, 36, 2572.

45 F. Elfarassi, L. Nabzar, E. Ringenbach and E. Pefferkorn, Colloids Surfaces A: Physicochem. Eng. Aspects, 1998, 131, 281.

46 B. V. Deryagin and L. D. Landau, Acta Physicochim. URSS., 1941, 14, 733.

47 E. J. W. Verwey and J. Th. G. Overbeek, Theory of the Stability of Lyophobic Colloids, Elsevier, Amsterdam, 1948.

48 M. M. Clark and P. Lucas, J. Membrane Sci., 1998, 143, 13.

49 K. L. Jones and C. R. O'Melia, J. Membrane Sci., 2000, 165, 31.

50 M. Kabsch-Korbutowicz, Materials Science-Poland, 2008, 26(2), 459.

51 F. Claret, T. Schäfer, A. Bauer and G. Buckau, Sci. Total Environ., 2003, 317, 189.

52 C. MacLeod and P. H. Whitfield, B.C., Northwest Sci., 1996, 70(1), $55-65$.

53 S. J. Markich and P. L. Brown, Sci. Total Environ., 1998, 217, 201.

54 M. Olías, J. M. Nieto, A. M. Sarmiento, J. C. Cerón and C. R. Cánovas, Sci. Total Environ., 2004, 333, 267. 